\title{
KORELASI ANTARA KADAR TRIGLISERIDA (TG) DENGAN PENYAKIT HIPERTENSI PADA MASYARAKAT DI WILAYAH KERJA PUSKESMAS BATUA KOTA MAKASSAR
}

The Correlation Between Triglyceride (TG) Levels And Hypertension Disease In The Community In The Working Area Of The Batua Health Center, Makassar City

\author{
Kalma $^{1}$, Muhammad Asikin ${ }^{2}$, Nur Adi ${ }^{3}$, Alfin Resya Virgiawan ${ }^{4}$ \\ ${ }_{1,3,4}$ Jurusan Analis Kesehatan Poltekkes Makassar \\ ${ }^{2}$ Prodi Keperawatan Parepare Poltekkes Makasar
}

Koresponden : kalmaanalis@gmail.com

\begin{abstract}
The Correlation Between Triglyceride (TG) Levels And Hypertension Disease In The Community In The Working Area Of The Batua Health Center, Makassar City. NonCommunicable Diseases (NCD) is one of the health problems that has become a national and global concern. Currently PTM is the leading cause of death in Indonesia. The situation where non-communicable diseases are still an important health problem and at the same time morbidity and mortality are increasing which is a double burden in health services. Thus causing a shift in the current pattern of disease. Hypertension is a condition in which a person experiences an increase in blood pressure above normal so that it can increase the risk of illness and death. Research has been carried out on the Correlation Between Triglyceride (TG) Levels and Hypertension Disease in the Community in the Working Area of Batua Health Center Makassar City. The purpose of this study is to describe the correlation between triglyceride levels and hypertension. The method used in determining triglyceride levels is by using the Strip method using the Cholesterol Auto Check tool. The sample used in this study were 39 people who were in the working area of the Mamajang Public Health Center in Makassar City with complaints of hypertension. Based on the results of the study, it was found that from 39 respondents there were 13 (33.3\%) respondents experiencing hypertriglyceridemia or triglyceride levels (TG) exceeding normal levels ( $200 \mathrm{mg} . \mathrm{dl}$ ), based on the results of statistical analysis with the Chii Square Fisher Exact test obtained a value of 0.289 and the value on Symmetric Measures is $0.388>(\dot{\alpha} 0.5)$, so it is recommended that every citizen who has hypertension always carry out regular health checks, especially triglyceride levels.
\end{abstract}

Keywords : Hypertension, Triglycerides

\begin{abstract}
ABSTRAK
Penyakit Tidak Menular (PTM) merupakan salah satu masalah kesehatan yang telah menjadi perhatian nasional maupun global. Saat ini PTM merupakan penyebab kematian terbanyak di Indonesia. Keadaan dimana penyakit tidak menular masih merupakan masalah kesehatan penting dan dalam waktu bersamaan morbiditas dan mortalitas makin meningkat yang merupakan beban ganda dalam pelayanan kesehatan. Sehinnga menyebabkan pergeseran pola penyakit saat ini. Hipertensi adalah keadaan dimana seseorang mengalami peningkatan tekanan darah diatas normal sehingga bisa meningkatkan resiko kesakitan dan kematian. Telah dilakukan penelitian tentang Korelasi Antara Kadar Trigliserida (TG) Dengan Penyakit Hipertensi Pada Masyarakat Di Wilayah
\end{abstract}


Kerja Puskesmas Batua Kota Makassar. Tujuan dari penilitian ini adalah mengetahui gambaran korelasi antara kadar Trigliserida dengan keadaan hipertensi. Metode yang digunakan dalam penentuan kadar Triglserida adalah dengan menggunakan metode Strip dengan menggunakan alat Auto Check Kolesterol. Sampel yang digunakan dalam penilitian ini adalah warga yang berada di wilayah kerja Puskesmas Mamajang Kota Makassar sebanyak 39 orang dengan keluhan hipertensi. Berdasarkan hasil penilitian didapatkan bahwa dari 39 responden terdapat $13(33,3 \%)$ responden mengalami Hipertrigliserida atau kadar Trigliserida (TG) melebihi dari kadar normal ( $\geq 200$ mg.dl), berdasarkan hasil analisis statistik dengan uji Chii Square Fisher Exact didapat nilai sebesar 0,289 dan nilai pada Symmetric Measures sebesar 0,388 > (́́ 0,5), sehingga disaran agar setiap warga yang mengalami hipertensi untuk senantiasa melakukan pemeriksaan kesehatan secara berkala terutam pemeriksaan kadar Trigliserida.

Kata kunci : Hipertensi, Trigliserida.

\section{PENDAHULUAN}

Hipertensi adalah keadaan dimana seseorang mengalami peningkatan tekanan darah diatas normal sehingga bisa meningkatkan resiko kesakitan dan kematian. Klasifikasi hipertensi sendiri dibuat berdasarkan tingkat tingginya tekanan darah yang mengakibatkan peningkatan risiko penyakit jantung dan pembuluh darah. Menurut Word Helth Organisation (WHO), batas tekanan darah yang masih dianggap normal adalah kurang dari 135/85 $\mathrm{mmHg}$ dan tekanan darah lebih dari 140/90 mmHg dianggap sebagai hipertensi. Penyakit Tidak Menular (PTM) merupakan salah satu masalah kesehatan yang telah menjadi perhatian nasional maupun global. Saat ini PTM merupakan penyebab kematian terbanyak di Indonesia. Keadaan dimana penyakit tidak menular masih merupakan masalah kesehatan penting dan dalam waktu bersamaan morbiditas dan mortalitas makin meningkat yang merupakan beban ganda dalam pelayanan kesehatan. Sehingga menyebabkan pergeseran pola penyakit saat ini (Beavers,.D.G, 2008).

Riskesdas 2018 menunjukkan prevalensi Penyakit Tidak Menular mengalami kenaikan jika dibandingkan dengan Riskesdas 2013, antara lain kanker, stroke, penyakit ginjal kronis, diabetes melitus, dan hipertensi.
Prevalensi kanker naik dari 1,4\% (Riskesdas 2013) menjadi 1,8\%, prevalensi stroke naik dari $7 \%$ menjadi $10,9 \%$; dan penyakit ginjal kronik naik dari $2 \%$ menjadi $3,8 \%$. Berdasarkan pemeriksaan gula darah, diabetes melitus naik dari 6,9\% menjadi 8,5\%; dan hasil pengukuran tekanan darah, hipertensi naik dari 25,8\% menjadi $34,1 \%$ (Kemenkes, 2018).

\section{METODE}

Penelitian yang digunakan
adalah metode analisis dengan
pendekatan Cross Sectional laboratorik
yang untuk mengetahui korelasi antara
kadar Trigliserida (TG) dengan tekanan
darah pada penderita Hipertensi di
wilayah Kerja Puskesmas Batua Kota
Makassar. Penelitian ini telah
dilaksanakan mulai tanggal 09 Juli 2020
sampai 9 Oktober 2020 di Puskesmas
Batua Kota Makassar.

\section{Populasi, Sampel dan Teknik Pengambilan Sampel}

Populasi dari penelitian ini adalah semua masyarakat diwilayah kerja Puskesmas Batua Kota Makassar. Sampel dalam penelitian ini adalah masyarakat diwilayah kerja Puskesmas Batua Kota Makassar dengan keluhan tekanan darah tinggi (Hipertensi). Pengambilan sampel dalam penelitian ini adalah secara Accidental sampling terhadap penderita Hipertensi. 


\section{Bahan dan Instrumen Penelitian}

Bahan penelitian ini adalah darah kapiler pasien, reagen siap pakai untuk pemeriksaan Trigliserida (TG), alkohol $70 \%$. Instrumen penelitian ini terdiri dari Auto clik lanset, lancet, spoit, torniquet, tabung vakum, sentrifus, mikropipet, tip, kapas alkohol, dan Alat autochek Trigliserida.

\section{Prosedur Kerja Penelitian}

\section{Pra Analitik}

Persiapan Pasien yakni Puasa $10-14$ jam termasuk menghentikan rokok dan olahraga tetapi diperbolehkan minum air putih. Tidak mendapat obat yang mempengaruhi kadar kolesterol dalam 2 minggu terakhir. Pasien dalam keadaan stabil, tidak ada perubahan berat badan, pola makan, kebiasaan merokok, minum kopi dan alkohol dalam 2 minggu terakhir sebelum tes. Pasien tidak sedang mengalami stres oleh penyakit akut.

Persiapan Sampel yakni waktu pengambilan sampel darah pasien dalam posisi duduk yang sudah dilakukan selama 5 menit. Pada saat pengambilan darah, pemasangan torniquet sebaiknya tidak lebih 1 menit. Serum sebaiknya dipisahkan dari sel darah merah sesegera mungkin. Sampel sebaiknya segera dites, tidak disimpan atau tidak dibekukan. Hindari sampel yang ikterus dan hemolisis karena dapat terjadi peningkatan palsu pada hasil tes.

\section{Analitik}

Pertama Tekan on/off, periksa Washer, Rinse, rak kuvet, reagen dan dilakukan kontrol sebelum alat digunakan, setelah semua selesai alat siap dioperasikan. Setelah itu strip kolesterol dimasukkan ke dalam alat auto Kolesterol. Kemudian ambil serum dengan menggunakan pipet volumetrik $20 \mu \mathrm{l}$. Sentuhkan ujung pipet pada stri kolesterol. Dibiarkan alatnya kulang lebih 20 detik dan nilainya akan tertera pada alat baca. Kemudian catat hasil yang tertera pada alat tersebut.

\section{Analisa Data}

Analisa data dalam penelitian ini yaitu dianalisis secara statistik menggunakan aplikasi SPSS dengan uji Chi Square dan disajikan dalam bentuk tabel yang dinarasikan.

\section{HASIL}

Berdasarkan hasil pemeriksaan kadar Trigliserida (TG) penderita hipertensi pada masyarakat di wilayah kerja Puskesmas Batua Kota Makassar yang dilaksanakan mulai tangal $14 \mathrm{Juli}$ sampai 09 September 2020, maka dari itu didapatkan hasil yaitu menunjukkan bahwa hasil pemeriksaan trigliserida pada penderita hipertensi di puskesmas batua kota Makassar dari 45 responden ditentukan berdasarkan jenis kelamin, umur, tekanan darah dan kadar trigliserida.

Sedangkan berdasarkan hasil pemeriksaan trigliserida pada penderita hipertensi di puskesmas batua kota Makassar menunjukkan bahwa dari 45 responden maka terdapat $13(28,9 \%)$ berjenis kelamin laki-laki dan 32 $(71,1 \%)$ berjenis kelamin perempuan.

Selanjutnya hasil distribusi responden berdasarkan kadar trigliserida pasien hipertensi di Puskesmas batua kota Makassar menunjukkan bahwa dari 45 responden terdapat $27(60 \%)$ kadar trigliserida normal dan 18 (40\%) kadar trigliserida tinggi.

Kemudian hasil distribusi responden berdasarkan jenis kelamin yang mengalami Hipertrigliseriuda menunjukkan bahwa dari 18 responden yang mengalami kadar Trigliserida Tinggi maka terdapat $5(27,8 \%)$ lakilaki dan $13(72,2 \%)$ perempuan. 


\section{PEMBAHASAN}

Hipertensi adalah suatu gangguan pada sistem peredaran darah yang sering terdapat pada usia setengah umur atau lebih tua. Menurut Word Health Organization (WHO), batas tekanan darah yang masih dianggap normal adalah 140/90 $\mathrm{mmHg}$ dan tekanan darah sama atau di atas 160/95 $\mathrm{mmHg}$ maka dianggap mengalami hipertensi atauntekanan darah tinggi. Kerja jantung terutama ditentukan oleh besarnya curah jantung dan tahanan perifer. Curah jantung pada pasien hipertensi umumnya normal. Kelainan terutama pada peningkatan tahanan perifer. Peningkatan tahanan perifer ini disebabkan karena penyempitan pembuluh darah akibat ketegangan otot polos pada pembuluh darah tersebut. Meningkatnya tekanan darah semakin menegangkan dinding pembuluh darah sehingga menyebabkan dinding pembuluh darah semakin tebal dan ronggan pembuluh darah semakin sempit yang meningkatkan tahanan terhadap mengalirnya darah Perubahan struktur inilah yang dianggap sebagai salah satu faktor utama sukarnya tekanan darah dikendalikan dengan obat-obatan anti hipertensi pada kasuskasus tertentu. Kerja jantung pada penderita hipertensi akan bertambah berat karena naiknya tahanan perifer yang lama kelamaan akan menyebabkan terjadinya hipertropi ventrikel kiri. Dengan adanya hipertropi dan hiperplasia ventrikel kiri maka sirkulasi darah dalam otot jantung tidak mencukupi lagi sehingga terjadi anoksia (kekurangan oksigen).Hal ini dapat diperberat oleh adanya sklerosis koroner dan jika hal ini berlangsung lama akan terjadi decompensasi cordis di samping ini juga akan menyebabkan gagal jantung. Pusat vasomotor di batang otak yang akibat terjadinya vasokontriksi arteri otak sistemik yang akan meningkatkan tekanan darah (Junaidi I, 2010).

Trigliserida adalah suatu ester gliserol. Trigliserida terbentuk dari 3 asam lemak dan gliserol. Apabila terdapat satu asam lemak dalam ikatan dengan gliserol maka dinamakan monogliserida. Fungsi utama trigliserida adalah sebagai zat energi. Lemak disimpan didalam tubuh dalam bentuk trigliserida. Apabila sel membutuhkan energi enzim lipase dalam sel lemak akan memecah trigliserida menjadi gliserol dan asam lemak sensial melepasnya kedalam pembuluh darah. Oleh sel-sel yang membutuhkan komponen-komponen tersebut kemudian dibakar dan menghasilkan energi, karbondioksida $\left(\mathrm{CO}_{2}\right)$ dan air $\left(\mathrm{H}_{2} \mathrm{O}\right)$ (Fenske,D.2005).

Trigliserida adalah salah satu jenis lemak yang terdapat dalam darah dan berbagai organ dalam tubuh. Dari sudut ilmu kimia trigliserida merupakan substansi yang terdiri dari gliserol yang mengikat gugus asam lemak. Makan makanan yang mengandung lemak akan meningkatkan trigliserida trigliserida dalam darah dan cenderung meningkatkan kadar kolesterol. Dan di dalam cairan darah trigliserida di kemas dalam bentuk partikel lipoprotein. Lipoprotein yang mengandung trigliserida terbesar adalah chylomicron (Mulyanto, D, 2016).

Berdasarkan hasil penelitian yang dilakukan terhadap 45 responden dengan keluhan penyakit tekanan darah tinggi di Puskesmas Batua Kota Makassar maka didapatkan bahwa responden laki-laki sebanyak 13 $(28,9 \%)$, dan perempuan sebanyak 32 $(71,1 \%)$. Dan dari hasil pemeriksaan Trigliserida didapatkan nilai terendah adalah $96 \mathrm{mg} / \mathrm{dl}$ dan nilai tertinggi adalah $531 \mathrm{mg} / \mathrm{l}$ dengan nilai rerata 208,1 mg/dl. Dari 45 responden didapatkan bahwa sebanyak 27 (60\%) responden dengan kadar Trigliserida < 
$200 \mathrm{mg} / \mathrm{dl}$, dan 18 (40\%) responden dengan kadar Trigliserida dengan kadar $200 \mathrm{mg} / \mathrm{dl}$.

Berdasarkan hasil penelitian Ikawati K, dkk, 2019) bahwa terhadap 40 responden didapatkan rerata kadar kolesterol pada penderita hipertensi stadium 1 sebesar $220.5 \mathrm{mg} / \mathrm{dL}$. Sedangkan rerata kadar kolesterol pada penderitahi pertensi stadium 2 sebesar $242 \mathrm{mg} / \mathrm{dL}$ atau lebih tinggi 9,8\%. Kadar trigliserida penderita hipertensi stadium 1 didapatkan rerata 160,4 $\mathrm{mg} / \mathrm{dL}$ dan rerata pada penderita hipertensi stadium 2 sebesar 238.1 $\mathrm{mg} / \mathrm{dL}$ atau lebih tinggi 48\%. Â Hasil uji korelasi terhadap kadar kolesterol didapatkan nilai $\mathrm{P}>0.05$ sedang untuk kadar trigliserida didapatkan $\mathrm{P}<0.05$ dan $\mathrm{R}=0.725$. Tidak terdapat hubungan yang bermakna antara kadar kolesterol total dengan derajat tekanan darah, tetapi terdapat hubungan positif kuat antara kadar trigliserida dengan tekanan darah. Semakin tinggi kadar trigliserida akan semakin tinggi derajad tekanan darahnya. Dari hasil tersebut dapat disimpulkan bahwa sebagian profil lipid berhubungan terhadap derajad tekanan darah pada penderita hipertensi di RSUD Tugu Semarang.

Berdasarkan hasil penilitian Dian Marta Sari (2016), bahwa dari 38 orang guru yang berusia diatas 40 tahun yang menjadi subjek penelitian, umumnya memiliki tekanan darah kategori Hipertensi Stadium 1 yaitu sebanyak 20 orang $(52,6 \%)$. Guru yang berusia diatas 40 tahun yang menjadi subjek penelitian umumnya memiliki kadar trigliserida puasa yang normal, yaitu 28 orang $(73,7 \%)$ dari 38 orang.

\section{KESIMPULAN}

Berdasarkan hasil dan pembahasan pada penilitian ini maka dapat ditarik kesimpulan bahwa dari 45 responden penderita hipertensi pada masyarakat di wilayah kerja Puskesmas
Batua kota Makassar terdapat kadar Trigliserida terendah adalah $96 \mathrm{mg} / \mathrm{dl}$ dan nilai tertinggi adalah $531 \mathrm{mg} / \mathrm{dl}$ dengan nilai rerata $208,7 \mathrm{mg} / \mathrm{dl}$, dan dari 45 responden terdapat $32(71,1 \%)$ orang mengalami kadar Trigliseriuda normal $(<200 \mathrm{mg} / \mathrm{dl})$ dan $13(28,9 \%)$ dengan kadar Trigliserida yang tinggi ( $\geq \mathrm{mg} / \mathrm{d} /$ ).

\section{SARAN}

Berdasarkan hasil dan pembahasan dari penilitian ini maka dapat disarankan sebagai berikut yaitu kepada warga masyarakat diharapkan agar senantiasa melakukan pemeriksaan kesehatan secara berkala dengan melakukan pemeriksaan tekanan darah dan kepada warga masyarakat yang mengalami tekanan darah tinggi (Hipertensi) agar senantiasa melakukan pemeriksaan kadar Trigliserida.

\section{DAFTAR PUSTAKA}

Agustiyanti, Putri Nurul, Sitti Fatimah Pradigdo, Rony Aruben, 2017. Hubungan Asupan Makanan, Aktivitas Fisik Dan Penggunaan Kontrasepsi Hormonal Dengan Kadar Kolesterol Darah Studi Pada Wanita Keluarga Nelayan Usia 30 - arwoz40 Tahun. JURNAL

Arisma,D,M, 2011. .Buku Ajar Ilmu Gizi, Buku Kedokteran EGC,Jakarta.

Beavers,.D.G, 2008. Tekanan Darah. Pt, Dian Rakyat, Jakarta

D. Baron, 1981. Patologi Klinik Edisi 4. EGC. Jakarta.Eleanor B daqn Jonathan M, 2007. Memahami Kolesterol. Erlangga. Jakarta

Fikri, Fairuz. 2009. Bahaya Kolesterol: Memahami, Mendeteksi, dan Mengontrol kolesterol. Katahati. Yogyakarta.

Junaidi I, 2010. Hipertensi. Pengenalan, Pencegahan, dan Pengobatan,.Klompok Gramedia, Egc.jakarta. 
Mahdiana, Ratna. 2010. Mencegah Penyakit kronis Sejak Dini. Tora Book. Yogyakarta.

Murray. Robert K., Daryl K. Granner, Dan Victor W. Rodwell. 2009. Biokimia Harper Edisi 27. Penerbit Buku Kedokteran ECG. Jakarta.

Putri Sitiatava Rizema. 2011. Tips Sehat dengan Pola Tidur yang Tepat Cerdas. Buku Biru. Yogyakarta.

Robert E., Kowalski, 2010. Terapi hipertensi: Program 8 Minggu Menurunkan Tekanan Darah
Tinggi Dan Mengurangi Resiko Serangan Jantung Dan Stroke Secara Alami. Bandung : Qanita Soen Briliantono M. 2013. Jangan Takut Sehat. Halimun Media Citra. Jakarta.

Shabela, Rifdah. 2012. Pahami, Waspadai, Segah, dan Musnahkan Kolesterol. Cable Book. Klaten. Jawa Tengah.

Yogiantoro M, 2009. Hipertensi Essensial : Buku Ajar Ilmu Penyakit Dalam. Pusat Penerbitan departemen Ilmu Penyakit dalam, FKUI 
Tabel 1

Hasil pemeriksaan Trigliserida pada penderita Hipertensi di Puskesmas Batua Kota Makassar.

\begin{tabular}{|c|c|c|c|c|}
\hline No & Jenis Kelamin & Umur & $\begin{array}{c}\text { Tekanan Darah } \\
\text { (Sistole/Diastole) }\end{array}$ & $\begin{array}{c}\text { Kadar } \\
\text { Trgliserida } \\
\text { (mg/dl) }\end{array}$ \\
\hline 1 & $\mathrm{~L}$ & 56 & $150 / 105$ & 214 \\
\hline 2 & $\mathrm{P}$ & 67 & $130 / 80$ & 197 \\
\hline 3 & $\mathrm{~L}$ & 72 & $123 / 70$ & 247 \\
\hline 4 & $\mathrm{P}$ & 66 & $138 / 85$ & 133 \\
\hline 5 & $\mathrm{P}$ & 33 & $170 / 90$ & 406 \\
\hline 6 & $\mathrm{~L}$ & 64 & $140 / 70$ & 120 \\
\hline 7 & $\mathrm{P}$ & 59 & $135 / 90$ & 136 \\
\hline 8 & $\mathrm{P}$ & 57 & $170 / 100$ & 166 \\
\hline 9 & $\mathrm{P}$ & 37 & $150 / 90$ & 194 \\
\hline 10 & $\mathrm{P}$ & 50 & $150 / 90$ & 136 \\
\hline 11 & $\mathrm{~L}$ & 69 & $135 / 83$ & 253 \\
\hline 12 & $\mathrm{P}$ & 63 & $190 / 80$ & 200 \\
\hline 13 & $\mathrm{P}$ & 54 & $129 / 85$ & 149 \\
\hline 14 & $\mathrm{P}$ & 53 & $140 / 90$ & 172 \\
\hline 15 & $\mathrm{~L}$ & 56 & $140 / 100$ & 160 \\
\hline 16 & $\mathrm{P}$ & 53 & $180 / 100$ & 254 \\
\hline 17 & $\mathrm{P}$ & 40 & $135 / 85$ & 496 \\
\hline 18 & $\mathrm{~L}$ & 72 & $130 / 70$ & 118 \\
\hline 19 & $\mathrm{~L}$ & 68 & $180 / 90$ & 99 \\
\hline 20 & $\mathrm{P}$ & 64 & $140 / 85$ & 96 \\
\hline 21 & $\mathrm{~L}$ & 60 & $140 / 100$ & 165 \\
\hline 22 & $\mathrm{P}$ & 56 & $145 / 80$ & 463 \\
\hline 23 & $\mathrm{~L}$ & 63 & $140 / 100$ & 192 \\
\hline 24 & $\mathrm{P}$ & 70 & $155 / 80$ & 150 \\
\hline 25 & $\mathrm{P}$ & 54 & $140 / 80$ & 124 \\
\hline 26 & $\mathrm{P}$ & 34 & $130 / 90$ & 154 \\
\hline 27 & $\mathrm{P}$ & 65 & $156 / 93$ & 182 \\
\hline 28 & $\mathrm{~L}$ & 58 & $140 / 90$ & 531 \\
\hline 29 & $\mathrm{P}$ & 57 & $146 / 85$ & 241 \\
\hline 30 & $\mathrm{P}$ & 57 & $133 / 80$ & 355 \\
\hline 31 & $\mathrm{P}$ & 78 & $140 / 95$ & 174 \\
\hline 32 & $\mathrm{P}$ & 73 & $145 / 100$ & 197 \\
\hline 33 & $\mathrm{P}$ & 49 & $180 / 80$ & 146 \\
\hline 34 & $\mathrm{P}$ & 63 & $128 / 90$ & 182 \\
\hline 35 & $\mathrm{P}$ & 57 & $140 / 90$ & 179 \\
\hline 36 & $\mathrm{~L}$ & 60 & $140 / 75$ & 225 \\
\hline 37 & $\mathrm{P}$ & 52 & $130 / 90$ & 252 \\
\hline 38 & $\mathrm{P}$ & 79 & $130 / 90$ & 138 \\
\hline 39 & $\mathrm{P}$ & 57 & $130 / 80 \backslash$ & 169 \\
\hline 40 & $\mathrm{~L}$ & 60 & $150 / 100$ & 200 \\
\hline 41 & $\mathrm{P}$ & 36 & $130 / 95$ & 216 \\
\hline 42 & $\mathrm{~L}$ & 52 & $140 / 90$ & 140 \\
\hline 43 & $\mathrm{P}$ & 38 & $130 / 90$ & 200 \\
\hline
\end{tabular}




\begin{tabular}{lllll}
\hline 44 & $\mathrm{P}$ & 40 & $145 / 100$ & 220 \\
45 & $\mathrm{P}$ & 59 & $130 / 90$ & 255 \\
\hline
\end{tabular}

Sumber : Data Primer 2020

Tabel 2

Distribusi responden berdasarkan jenis kelamin pasien hipertensi di Puskesmas Batua Kota Makassar.

\begin{tabular}{ccc}
\hline Jenis Kelamin & N & \% \\
\hline Lakai-Laki & 13 & 28,9 \\
\hline Perempuan & 32 & 71,1 \\
\hline Total & 45 & 100
\end{tabular}

Sumber : Data primer 2020

Tabel 3

Distribusi responden berdasarkan kadar Trigliserida pasien hipertensi di Puskesmas Batua Kota Makassar.

\begin{tabular}{ccc}
\hline Kadar Trigliserida & n & \% \\
\hline Normal $(<200 \mathrm{mg} / \mathrm{dl})$ & 27 & 60 \\
\hline Tinggi $(\geq 200 \mathrm{mg} / \mathrm{dl})$ & 18 & 40 \\
\hline Total & 45 & 100 \\
\hline
\end{tabular}

Tabel 4

Distribusi responden berdasarkan jenis kelamin yang mengalami Hipertrigliseriuda

\begin{tabular}{ccc}
\hline Kadar Trigliserida Tinggi & $\mathbf{n}$ & $\mathbf{\%}$ \\
\hline Laki - Laki & 5 & 27,8 \\
\hline Perempuan & 13 & 72,2 \\
\hline Total & 18 & 100 \\
\hline
\end{tabular}

Sumber : Data primer 2020 